\title{
Book Review: First Principles of Instruction - Identifying and Designing Effective, Efficient, and Engaging Instruction
}

\author{
Necip Serdar Sever \\ Anadolu University, Turkey
}

Education and time spent on learning is always pays back, right? Does professional looking instructional media means effectiveness? Is education and training are the same? Perhaps many questions popping up in our minds similar to that nature. In many cases, technology becomes a savior for those of us whom may have more questions than answers. E-learning and other fancy gagetary mock ups can dazzels many eyes, nonethless it's not sufficent for easing up pains in many hearts and minds.

Professor David Merrill, a distinguished scholar in the instructional design field calls e-learning as e3 effective, efficient, and engaging learning environment, content, and design. First Principles of Instruction: Identifying and Designing Effective, Efficient, and Engaging Instruction is published by Pfeiffer Publishing in 2012. The first edition of this book is intented to identify and design e3 instruction in all instructional settings, for learners of any age, and for all subject-matter areas, both in training and education.

Many valuable researchers, academics, and respectful scholars produce very illuminating studies, by the same token academia fails short in most times to come up with practically applicable theories, models or ideas. This is the start point of this book as the author stated. Merrill, by pressing his finger to this fact by stating that he in 2002 published a paper in Educational Technology Research and Development titled First Principles of Instruction. Although the principles written in the paper seemed obvious to many practitioners, applying these principles to instructional designs appeared complex. This book was written to bring more of an applicabilitiy of design and instruction principles written in that journal article.

This book is organized in three parts. Part I: Identifying e3 Instruction. Part II: Designing e3 Instructions. Part III: Support for First Principles of Instruction. The first part describes the principles and draws a road map as to how to critique existing courses, modules or lessons in the line of examing their effectiveness, efficiency, and engagement. Second part provides guidance in how to design instruction to incorporate design principles. Third part includes how to use research to support or iterate instructions and designs that are already in use. The last part also covers evaluations and implementations of instructional theories and their use.

The organization of this book is unique and enables the reader become self sufficient both for academic and paractical uses. Chapters begin with a pleriminary figure that relates terminology, concepts, and principles and incorporates them with previous and subsequent chapters in the book. Quick Look section aims to answer questions related to the chapter. Key Words section includes initial vocabulary used in the chapter and helps reader to better understand the content. Examples for better understaning the principles of instruction and 
design are added to each chapter. These examples consists vast array of courses from variety of disciplines and careful examination of these examples helps readers to understand basic principles stated in the book. Application sections are very useful for practical application of skills acquired from each chapter. Principles and Strategies sections summarizes principle in the chapter and elaborates on application of those principles into a practical strategy for daily life. To Learn More section includes references and sources if reader wants further resources for reading on the subject matter. Coming Next section introduces the next chapter and explains how it builds on the current chapter.

Clearly, this is a how to book and it contemplates first on how to identify e3, effectiveness, efficient, and engaging. Then, exemplifies how to design instruction around these principles. Principles can be implemented in many ways. Under no circumstances the author intends to say that strategies in this book are the only available ones in the field. The only concern of the author is to make it clear that the strategies in this book are the ones that appropriately implement the First Principles of Instruction.

Merrill includes three levels of discourse in conveying his model. These are principles, prescriptions, and practices. Principles are relationships that are applicable to wide variety of settings, populations, and instructional approaches. Because principles are abstract and thus open to misinterpretations, use of prescriptions would substantially reduce risks and make principles come to a life more effectively. Note that, the prescriptions in this book are not the only way to utilize principles. Other scholars and practitioners may come up with more practical and applicable prescriptions based on their own experiences. In some practitioners even prescriptions may seem more of an abstract to implement. If this is the case, then readers may find practices pretty handy because the practices in the book covers actual instructional events from daily applications.

The book consists of ten chapters organized under three different sections. Chapter 1 is titled as What Are the Problems with Instructions? This chapter not only introduces most common instructional mistakes but also raises a number of frequently asked questions about instruction. This chapter also aims to a indicate possible mistakes and how to avoid them. The chapter attempts to answer some questions. Some of these questions include the following: Is training education? Do Today's Technologies Require New Instructional Strategies? Have Learners Changed? What are Some Common Instructional Mistakes? Is Information Instruction? As seen from these examples, such questions will certainly help broaden the discussions in the subsequent chapters.

Chapter 2, First Principles of Instruction demonstrates five categories of instructional activities that promote effective, efficient, and engaging learning. The categories are demonstration, application, problem-centered, activation, and integration. These principles are then explained and its applications are demonstrated on a sample course. A step by step approach is used in a sample First Aid course to demonstrate the reader how these instructional activities can engage in real life course design. The chapter includes visuals, problems, and solutions built around the sample course.

Chapter 3, Instructional Content contains and explains five types of component skills to solve a complex problem. These skills are information-about, part-of, kind-of, how-to, and whathappens. Each of these skills are then matched with appropriate e3 principle and explained how it can be utilized in real life setting. 
Chapter 4, Instructional Interaction demonstrates instructional model with components of tell, show, ask, and do that in and around of content from an actual instructional event. This chapter also includes various features of demonstration principle such as guidance and effective multimedia implementation. The chapter incorporates some of the features of application principles as well. These are the coaching and feedback elements of application principle.

Chapter 5, Instructional Strategy includes and demonstrates how instructional content and interaction are combined into prescribed sets of instructional events. These contents and events should be structured in a form of integartion and should demonstrate strong unity in readers' mind.

Chapter 6, Instructional Strategy for Problem Solving shows how instructional strategies related to individual skills work together to provide an integrated problem solving strategy at individual and corporate levels. Using prescription methodology, the chapter explains a set of instructional events for reader to use overcoming a problem.

Chapter 7, Problem-Centered Instructional Strategy demonstrates the differences between topic oriented and problem progression based course structures. The chapter then exempfies how tell-show-do instructional strategy can be utilized in progression stages of a problem solving based courses or modules.

Chapter 8, Enhancing Instructional Strategies with Structural Frameworks and Learner Interaction demonstrates some of the effective ways to use a structural farmework to provide learner guidance. Such guidance is critical especially when learner needs to acquire content for his or her new skills. This chapter also incorporates how to integrate social interaction into e3 instruction. Such incorporation includes peer-sharing, peer-discussion, peer-collaboration, and peer-critique.

Chapter 9, Multimedia Implementation of Instructional Strategies explaines how to use multimedia effectively to implement appropriate instructional strategies. Multimedia use under no circumstances should precedes the relevant content and its personalized delivery to audiences.

Chapter 10, Critiquing Instructional Strategies in Existing Instruction provides a checklist that will facilitate evaluation of existing courses or modules. These checklists will help the reader to evaluate the course, material, and goals instructed in previous chapters. The checklist also helps to evaluate a course or module based on e3 criteria.

All in all, this book is very conscise and provides compact solutions for designing a course or module in instructionally sound ways. A more of a positive aspect for the book is that it uses real life course examples, a rather step by step road map for readers as to how to develop an instructional system based on principles that are put forward in the book. However, just as any work, scholarly or practically, this book has some setbacks.

By providing a procedural step by step approach, the author merely covered all areas of instructional design and thus this might lead the reader to think that no other alternative ways or approaches applicable. 
As a second limitation may be that the whole structure of the book and all the examples of instructional designs are based on the North American cultural settings. Cultural differences may represent "road maps" for readers merely not applicable in different cultures. As the author stated several times throughout the book, individual differences, skill sets, thinkings, and corporate as well as national cultural discrepancies may be major obstacles when comes to implementations.

Despite these minor criticisms, this book serves the instructional design community worldwide and deserves a sincere salute from academics and practitioners as lifetime students of the field. The book can also be considered one of the master pieces of Professor Merrill as a seasoned scholar, researcher, and designer.

Correspondence: Necip Serdar Sever, Associate Professor, Institute of Communication Sciences, Anadolu University, Yunus Emre Campus, Eskisehir, Turkey 